\title{
Screening cellular proteins involved in the anti-proliferative effect of the ADAM15 disintegrin domain in murine melanoma cells
}

\author{
JING WU ${ }^{1,2}$, LIANFEN ZHANG ${ }^{1,2}$, XIAOFENG MA ${ }^{1,2}$, XIAOPING ZHANG $^{1,2}$ and JIAN JIN ${ }^{1,2}$ \\ ${ }^{1}$ School of Medicine and Pharmaceutics, ${ }^{2}$ The Key Laboratory of Industrial Biotechnology, \\ Ministry of Education, Jiangnan University, Wuxi, Jiangsu 214122, P.R. China
}

Received February 21, 2008; Accepted May 5, 2008

DOI: $10.3892 /$ or_00000058

\begin{abstract}
A disintegrin and metalloprotease protein 15 (ADAM15), a membrane-anchored glycoprotein, is believed to function in cell-cell interactions via an integrin binding motif within its disintegrin domain. To screen its target proteins, the recombinant ADAM15 disintegrin domain (RADD) was expressed in Escherichia coli, biotinylated and used in a protein pull-down assay in vitro. A total of eight kinds of proteins were identified by 2DE/LC-MS-MS. One of them, p38 kinase, was selected for further investigation of its involvement in the anti-proliferative effect of RADD on melanoma cells. Phosphorylation of p38 kinase in melanoma cells was detected upon treatment with RADD. Furthermore, the suppression of p38 kinase activity resulted in a decrease in the RADD inhibitory effect on melanoma cell proliferation. These results provide evidence that RADD inhibits melanoma cell proliferation partly through p38 kinase activation.
\end{abstract}

\section{Introduction}

ADAMs (a disintegrin and metalloproteinases) are transmembrane glycoproteins that are implicated in diverse biological processes including proteolysis, cell adhesion, cell fusion, protein ecto-domain shedding and intracellular signaling (1). They contain multiple functional domains: a pro-domain, a metalloproteinase, a disintegrin domain and a cysteine-rich region containing an epidermal growth factor (EGF) repeat and a transmembrane domain (2). Among all of the known human ADAMs, ADAM15 (metargidin) is unique since it has an RGD (Arg-Gly-Asp) motif, an amino acid hairpin loop maintained by disulfide bridges, in its disintegrin-

Correspondence to: Dr J. Jin, School of Medicine and Pharmaceutics, Jiangnan University, 1800 Lihu Road, Wuxi, Jiangsu 214122, P.R. China

E-mail: jinjian31@hotmail.com

Key words: a disintegrin and metalloprotease protein 15 disintegrin domain, anti-proliferative effect, melanoma cell, target protein like domain. This RGD motif enables selective binding to integrins, a family of heterodimeric and transmembrane receptors that play key roles in the signaling networks $(2,3)$.

The interaction of ADAM15 with integrin $\alpha_{v} \beta_{3}$ has been proven to be important in several biological processes, as $\alpha_{v} \beta_{3}$ is implicated in diverse functions including angiogenesis, tumor cell metastasis and osteoporosis $(2,4)$. Integrin $\alpha_{v} \beta_{3}$ is expressed by various cell types and has several ligands, including extracellular matrix molecules such as vitronectin and cell surface proteins such as CD31 (5). ADAM15 was also found to adhere to melanoma cells via $\alpha_{v} \beta_{3}$ and increased expression of $\alpha_{v} \beta_{3}$ in these cells is positively correlated with increased malignancy (4). The human recombinant ADAM15 disintegrin domain (RADD) has been considered as a potential intrinsic inhibitor of angiogenesis, tumor growth and metastasis (6). One of the anti-cancer mechanisms involving the ADAM15 disintegrin domain was thought to be related to its integrin-binding activity. It can interact with integrin to loosen tumor cell adhesion to the underlying matrix and then prevent tumor progression (7). However, it is conceivable that the ADAM15 disintegrin domain might also interact with other cellular proteins to exert biological functions. The identification of novel binding proteins will facilitate the investigation of the anti-cancer mechanisms that engage the ADAM15 disintegrin domain. Although, few studies on binding partners have been published.

The protein affinity pull-down assay is a traditional method for investigating protein-protein interactions (8). Two-dimensional electrophoresis (2DE) is the standard method for high resolution protein separation (isoelectric focusing/SDS-PAGE). Liquid chromatography with electrospray ion trap mass spectrometry (LC-ESI-MS) has some advantages in minimal protein quantification because of its high sensitivity compared with MALDI-TOF-mass spectrometry. The combination of the protein pull-down assay and the 2DE-MS approach is powerful and has been successful in many studies $(9,10)$.

In this study, eight kinds of proteins were screened and identified from whole cell extracts by the in vitro protein pull-down assay and 2DE/LC-MS analysis. Then, the influence of the cytoplasmic protein, p38 kinase, on the RADD treatment 
of melanoma cells was carefully investigated. The results demonstrate for the first time that p38 kinase is involved in the RADD anti-proliferation effect.

\section{Materials and methods}

Materials, strains and cells. Streptavidin MagneSphere ${ }^{\circledR}$ Paramagnetic Particles, MTT [3-(4,5-dimethylthiazol-2-yl)2,5-diphenyltetrazolium] and dimethyl sulfoxide (DMSO) were purchased from Promega (USA). ProtOn Biotin Labeling kit was purchased from Vector (USA). Integrin $\alpha_{v} \beta_{3}$, anti- $\alpha_{v} \beta_{3}$ monoclonal antibodies and human vitronectin were from Chemicon (USA). The synthetic peptides Gly-Arg-Gly-AspSer (GRGDS) and Ser-Asp-Gly-Arg-Gly (SDGRG) and the p38 inhibitor, SB203580, were purchased from Sigma Chemicals (USA). E. coli Rosetta (DE3) (Invitrogen) used to express RADD protein was cultivated in a Luria-Bertani (LB) medium with ampicillin $(100 \mu \mathrm{g} / \mathrm{ml})$ and chloramphenicol $(50 \mu \mathrm{g} / \mathrm{ml})$. Murine melanoma cells (B16F10) were maintained as a monolayer culture in RPMI-1640 medium supplemented with $10 \%$ fetal bovine serum (FBS) and antibiotics (100 U/ml penicillin, $100 \mathrm{mg} / \mathrm{ml}$ streptomycin and $2 \mathrm{mM}$ L-glutamine; purchased from Gibco Co. Ltd.) at $37^{\circ} \mathrm{C}$ in a humidified atmosphere with $5 \%(\mathrm{v} / \mathrm{v}) \mathrm{CO}_{2}$.

Expression and purification of RADD protein. The cDNA that encodes the entire disintegrin domain of ADAM15 was inserted into the pGEX-4T-1 vector and transformed into E. coli Rosetta (DE3). The fusion protein glutathione Stransferase (GST)-RADD was expressed by incubating the bacteria in $0.1 \mathrm{mM}$ isopropyl-1-thio-ß-D-galactopyranoside (IPTG, Sigma) for $6 \mathrm{~h}$. GST-RADD was extracted by sonication of the bacteria and purified by glutathione Sepharose 4B affinity chromatography (Pharmacia). RADD was released from GST-RADD by thrombin cleavage (10 units thrombin/1 mg fusion protein) at $4^{\circ} \mathrm{C}$ for $8 \mathrm{~h}$. The resulting protein mixture was further separated by Sephadex G-75 gel filtration chromatography (500 g, Pharmacia). The purified RADD was concentrated and its concentration was determined by BCA assay (Pierce). The molecular weight of RADD was analyzed by mass spectroscopy by the Shanghai Applied Protein Technology Co., Ltd., (P.R. China). The specificity of RADD was determined by Western blot analysis using an anti-human ADAM15 ectodomain antibody (R\&D Systems Co., Ltd.,) according to the standard procedure (11).

Integrin binding assay. Solid-phase binding assays were performed (12). Microtiter plates were coated overnight with purified human vitronectin $(10 \mu \mathrm{g} / \mathrm{ml})$ and blocked with $5 \%$ BSA (Sigma) in TACTS buffer [20 mM Tris-HCl (pH 7.5), $0.02 \%$ sodium azide, $2 \mathrm{mM}$ calcium chloride, $0.05 \%$ Tween-20 and $150 \mathrm{mM}$ sodium chloride] for $2 \mathrm{~h}$. Samples (RADD protein, GRGDS peptide or SDGRG) were incubated with $\alpha_{v} \beta_{3}(40 \mu \mathrm{g} / \mathrm{ml})$ in TACTS buffer for $15 \mathrm{~min}$ and added to the assay plates. The GRGDS and SDGRG peptides were used as positive and negative controls, respectively. After $2 \mathrm{~h}$ of incubation, mouse anti-human $\alpha_{v} \beta_{3}$ antibody was added and the mixture was incubated for a further $2 \mathrm{~h}$. The wells were washed three times and HRP-conjugated goat anti-mouse IgG (Cell Signaling, USA) was added and incubated for $2 \mathrm{~h}$. The wells were then washed four times with a phosphate buffer solution (PBS with $0.05 \%$ Tween-20) and the color was developed using O-phenylenediamine dihydrochloride (OPD) substrate (Sigma, St. Louis, USA). The absorbance was read at $450 \mathrm{~nm}$ on a multi-well microtiter plate reader.

Preparation of the whole melanoma cell extracts. Melanoma cells were synchronized with $2 \%$ FBS and then grown in a complete medium to reach $60-70 \%$ confluence in $10-\mathrm{cm}$ tissue culture plates. The cells were then treated with RADD $(5 \mu \mathrm{g} /$ $\mathrm{ml}$ ) for $24 \mathrm{~h}$, the medium was removed and the cells were rinsed twice with pre-chilled PBS. A chilled lysate buffer (13) (1 ml of $20 \mathrm{mM}$ Tris- $\mathrm{HCl}, \mathrm{pH} 7.5,120 \mathrm{mM} \mathrm{NaCl}, 10 \%$ glycerol, $1 \mathrm{mM} \mathrm{Na} \mathrm{VO}_{4}, 2 \mathrm{mM}$ EDTA, $1 \mathrm{mM}$ PMSF, $1 \%$ Triton X-100) was added to the plate, after which the cells were scraped from the plate and transferred to $10-\mathrm{ml}$ tubes to which $0.2 \mathrm{ml}$ of acid-washed glass beads were added. Each tube was then vortexed 10 times for $20 \mathrm{sec}$, with 2 min of incubation on ice between vortexing steps to minimize protein denaturation. The tubes were centrifuged at 1,500 x $\mathrm{g}$ for $5 \mathrm{~min}$ at $4^{\circ} \mathrm{C}$ and the supernatant was clarified by centrifugation at $15,000 \mathrm{x} \mathrm{g}$ for $20 \mathrm{~min}$ at $4^{\circ} \mathrm{C}$. The supernatants were then collected and mixed well and aliquots were placed in $1.5-\mathrm{ml}$ microfuge tubes and stored at $-80^{\circ} \mathrm{C}$.

Separation of binding protein on RADD affinity beads. The RADD protein was biotinylated using the ProtOn Biotin Labeling kit, following the manufacturer's instructions. Biotinylated RADD (b-RADD; $1 \mathrm{ml}, 100 \mu \mathrm{g} / \mathrm{ml}$ ) was added to $250 \mu \mathrm{l}(7.5 \mathrm{mg})$ of streptavidin-coated magnetic beads and gently mixed at $4^{\circ} \mathrm{C}$ for $2 \mathrm{~h}$ to effect linkage. The RADD affinity beads were separated by a magnet and washed with tris-buffered saline (TBST; $50 \mathrm{mM}$ Tris- $\mathrm{HCl}, \mathrm{pH} 7.5,150 \mathrm{mM}$ $\mathrm{NaCl}, 0.05 \%$ Tween-20). Melanoma cell lysates ( $1 \mathrm{ml}, 100 \mu \mathrm{g} /$ $\mathrm{ml})$ were mixed with prepared RADD affinity beads $(250 \mu \mathrm{l})$, with gentle shaking at $4^{\circ} \mathrm{C}$ overnight. The RADD affinity beads were washed with TBST ( $\mathrm{pH}$ 7.5) six times to remove nonspecifically bound proteins. The binding protein was then eluted with glycine buffer at $\mathrm{pH} 4.0,3.0$ and 2.0, and concentrated before the next separation.

Two dimensional electrophoresis and mass spectroscopy. Samples were diluted to $125 \mu \mathrm{l}$ with the re-hydration solution and loaded on 7-cm, pH 3-10, IPG strips (Bio-Rad). The total Vh was 24,000. The one-dimensional IEF was performed according to the manufacturer's protocol. Following IEF separation, the IPG strips were reduced and alkylated and the detergent was exchanged using a two-step equilibration solution. The second dimension was carried out on $12.5 \%$ SDS-PAGE at $10 \mathrm{~mA} / \mathrm{gel}$ and then at $20 \mathrm{~mA} / \mathrm{gel}$ constant current at room temperature until the dye front reached the bottom of the gels. The gels were stained by the silver-staining method and scanned using a GS-800 calibrated densitometer (Bio-Rad) before analysis using PDQUEST (version 7.0, Bio-Rad) and were then analyzed by mass spectroscopy at the Shanghai Applied Protein Technology Co., Ltd., (P.R. China).

Cell proliferation assay. Melanoma cells were first cultured in $2 \%$ FBS to induce the cells to accumulate at the $G_{0}-G_{1}$ phase, pretreated with or without the p38 inhibitor, SB203580, 


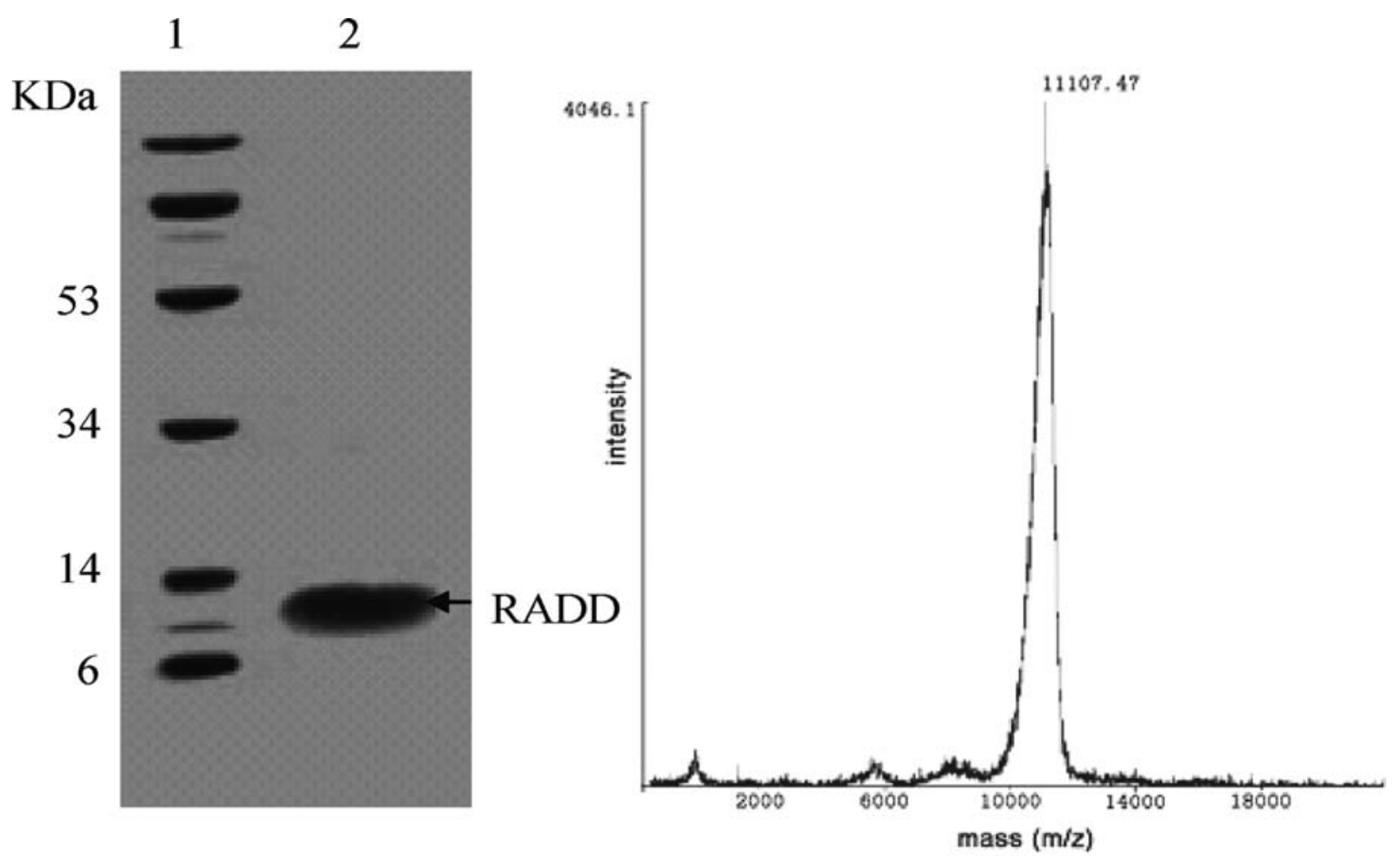

A

B

Figure 1. (A) Western blotting of RADD with anti-human ADAM15 ectodomain antibody (1:1000): 1 Marker; 2 RADD. (B) Mass spectrometry of RADD. The average mass of the large peak indicates the molecular weight of the RADD protein is 11,107.47.

$(0.5 \mu \mathrm{M})$ for $30 \mathrm{~min}$ at $37^{\circ} \mathrm{C}$ and then seeded into $96-$ well plates $\left(5 \times 10^{3}\right.$ cells/well $)$ in a complete medium. RADD at different concentrations $(0-10 \mu \mathrm{g} / \mathrm{ml})$ was added when the cells began to grow exponentially. Cell growth was determined using the standard MTT assay (14). The results presented are the mean values of four separate experiments.

Protein kinase assay. Melanoma cells were synchronized in $2 \%$ FBS and treated with different concentrations of RADD $(0-10 \mu \mathrm{g} / \mathrm{ml})$. After $24 \mathrm{~h}$ of incubation, the cells were harvested and lysed using the method mentioned above. Equivalent amounts of cellular proteins were subjected to $12 \%$ SDSPAGE and the subsequent Western blotting analysis was performed as previously described (11). The blots were scanned and then analyzed by spot densitometry using the Tanon Documentation and Analysis Soft (Tanon Technical Co., Shanghai, P.R. China).

Statistical analysis. One-way analysis of variance was performed to determine the significance between the groups. A p-value of $<0.05(\mathrm{P}<0.05)$ was considered as statistically significant. All of the figures shown in this report were obtained from at least three independent experiments with a similar pattern.

\section{Results}

Preparation and characterization of RADD. The soluble GST-RADD protein expressed in recombinant $E$. coli Rosetta (DE3) was obtained by glutathione-agarose affinity chromatography and cleaved by thrombin. Further purification

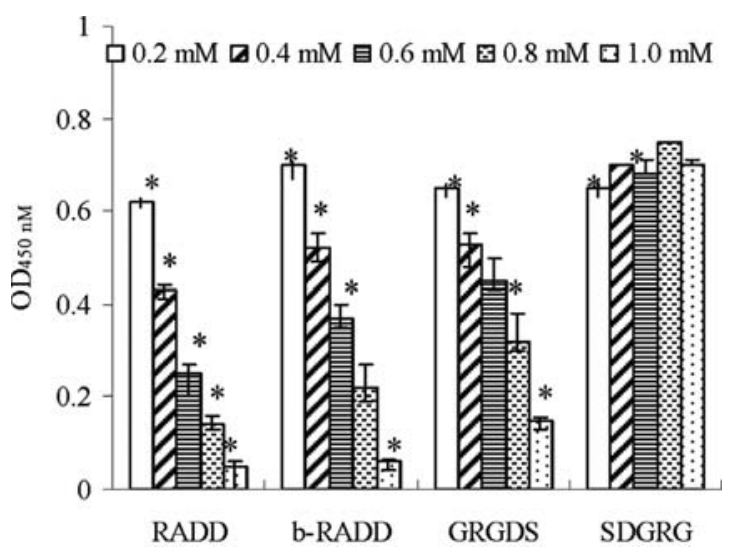

Figure 2. Integrin binding assay measured by solid-phase ELISA. Microtiter plates (96-well) were coated with human vitronectin. After blocking and washing, the plates were incubated with integrin $\alpha_{v} \beta_{3}$ in the presence of RADD, b-RADD, the peptide GRGDS or SDGRG at different concentrations (0.2-1.0 mM). After incubation, mouse anti-human $\alpha_{v} \beta_{3}$ antibody was added. Following further incubation, goat anti-mouse IgG HRP was added. Data are representative of three independent experiments with similar qualitative results. ${ }^{*} \mathrm{P}<0.05$ vs. the negative control (peptide SDGRG-treated).

was conducted to remove thrombin and the fused GST by Sephadex G-75 gel filtration chromatography. Purified RADD migrated as a single band on tricine gel and no residual GSTRADD was detected by immunoblotting using anti-human ADAM15 ectodomain antibody (Fig. 1A, lane 2). The molecular weight of the RADD protein as determined by MALDI-MS analysis was $\sim 11,107$, consisting of a single predominant peak (Fig. 1B). The purified RADD protein was 

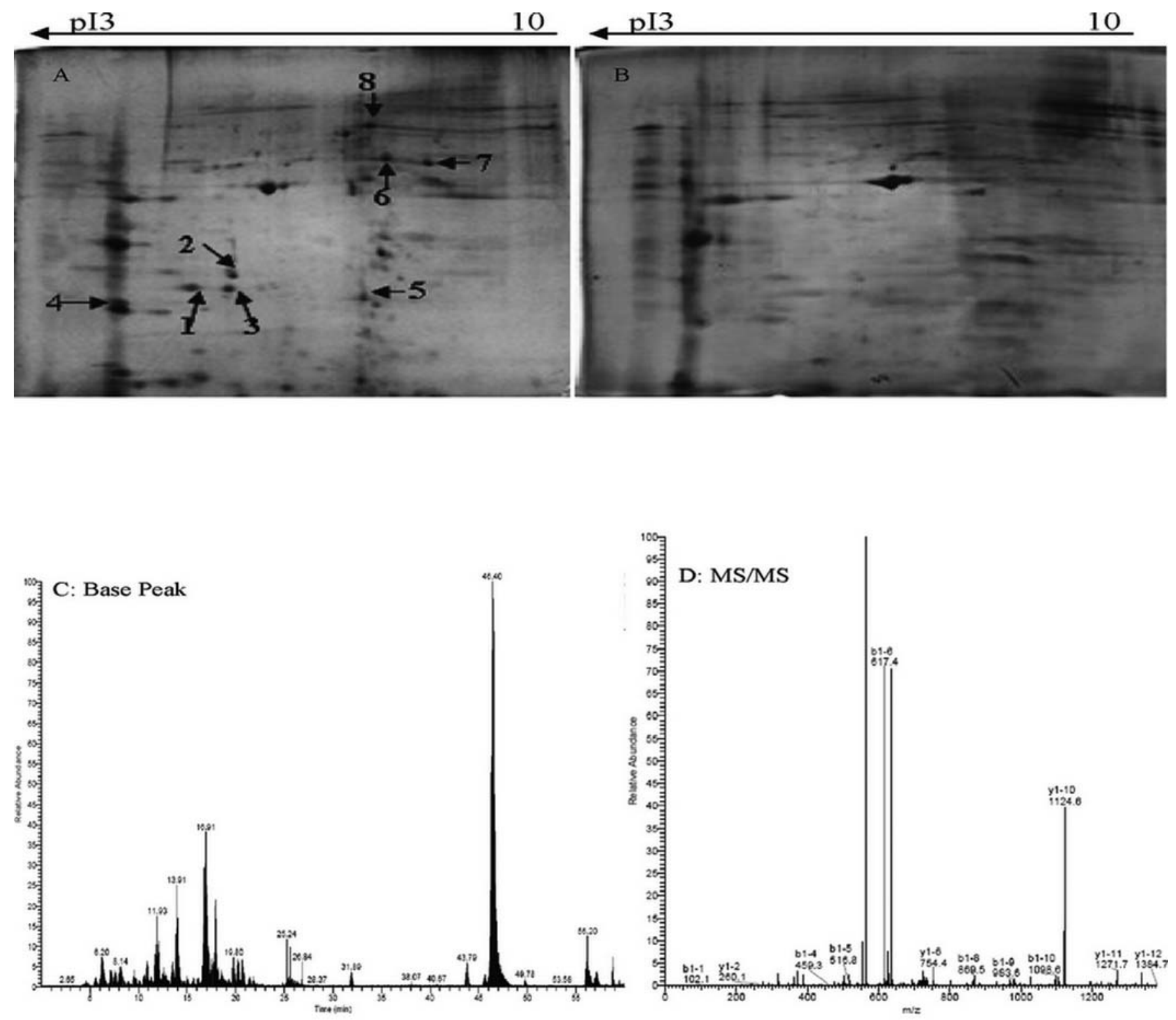

Figure 3. 2DE and LC-MS/MS analysis of RADD binding proteins. (A) b-RADD. (B) Streptavidin linked biotin as the control. The gels were stained by a modified silver-staining method and protein spot digests and LC-MS/MS analyses were performed as described in Materials and methods. Arrows indicate specific binding proteins of RADD, which are listed in Table I. (C) An example of a base peak map of p38 kinase. (D) An MS/MS map of the peptide TLFPGTDHIDQLK, which led to the identification of p38 kinase.

then biotinylated according to the protocol of the Biotin Labeling kit.

A solid-phase binding assay was used to investigate whether RADD or b-RADD interacts with integrin $\alpha_{v} \beta_{3}$ and inhibits integrin $\alpha_{v} \beta_{3}$ binding to vitronectin. The synthetic peptide GRGDS (Sigma) is known to have the ability to inhibit $\alpha_{v} \beta_{3}$ binding, while the reverse SDGRG does not. As shown in Fig. 2, RADD significantly and dose-dependently inhibited $\alpha_{v} \beta_{3}$ binding. At RADD concentrations of $0.4,0.6$ and $0.8 \mathrm{mM}$, the inhibitory rates were $38.6,62.3$ and $80.1 \%$, respectively, which were all higher than the corresponding values using commercial GRGDS. A similar phenomenon was also observed for the b-RADD case. These results indicated that the RADD protein structure does not change after biotinylation and that b-RADD can be used for further study.
Affinity capture and identification of target proteins. b-RADD was immobilized on the streptavidin-coated magnetic beads to screen the cellular binding proteins in vitro. The captured proteins from the RADD affinity beads and biotin-streptavidin beads (control) were resolved by SDS-PAGE and then by 2DE. The images from the two groups were compared by computerized image analysis (Fig. 3A and B). Eight protein spots showing significant and reproducible changes in the RADD-treated sample were picked out and subjected to in-gel digest and peptide mass fingerprinting analysis via mass spectrometer (LC-MS/MS) for identification (Fig. 3C and D). The peptide masses obtained were searched in the SwissProt/ TrEMBL database and closely matched values were taken into account for protein identification. After mass spectrometry analysis (Table I), eight protein spots were identified as: i) the mitogen-activated protein kinase 14 (p38 kinase), which participates in the MAPK signal transduction pathway; ii) 
Table I. Identification of the RADD binding proteins on melanoma cells.

\begin{tabular}{llcccc}
\hline Spot & \multicolumn{1}{c}{ Description } & Accession No. & $\mathrm{pI}$ & $\mathrm{Mr}(\mathrm{kDa})$ & Sequence coverage (\%) \\
\hline 1 & p38 kinase & $\mathrm{P} 47811$ & 5.55 & 41.3 & 20.28 \\
2 & Triosephosphate isomerase & $\mathrm{P} 17751$ & 6.90 & 46.7 & 12.85 \\
3 & $\alpha$-enolase & $\mathrm{P} 17182$ & 6.37 & 40.1 & 38.94 \\
4 & Tropomyosin 3 & $\mathrm{P} 21107$ & 4.90 & 30.9 & 25.00 \\
5 & Hemoglobin subunit B-1 & $\mathrm{P} 02088$ & 7.13 & 32.8 & 15.65 \\
6 & Glutamate dehydrogenase 1, & $\mathrm{P} 26443$ & 8.05 & 61.3 & 18.91 \\
7 & Malate dehydrogenase 2 & $\mathrm{Q} 0 \mathrm{QF} 44$ & 8.93 & 35.6 & 40.25 \\
8 & Glyceraldehyde-3-phosphate dehydrogenase & $\mathrm{P} 16858$ & 8.44 & 55.4 & 25.53 \\
\hline
\end{tabular}
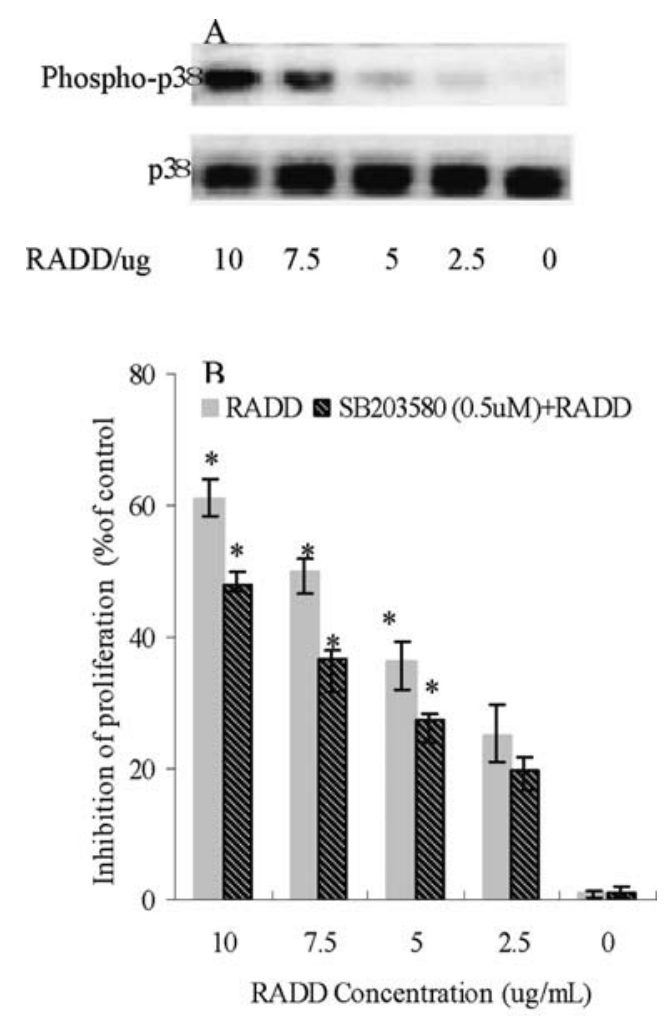

Figure 4. The involvement of P38 kinase in the anti-proliferative effect of RADD in melanoma cells. (A) RADD induced p38 activation in B16 F10 cells. The cells were treated with RADD at a concentration of $0-10 \mu \mathrm{g} / \mathrm{ml}$ for $24 \mathrm{~h}$. For analysis of phospho-p38 (indicating p38 activation) and p38 levels, whole-cell lysates were prepared and proteins were separated by SDS-PAGE, followed by immunoblotting using specific antibodies against phospho-p38 and p38, respectively. Antigen-antibody complexes were stained with an HRP-conjugated antibody and enhanced chemiluminescence reagent. (B) The p38 inhibitor, SB203580, decreased the inhibitory effect of RADD on $\mathrm{B} 16 \mathrm{~F} 10$ proliferation. B16F10 cells $\left(5 \times 10^{3}\right.$ cells/well) seeded in 96 -well plates were pretreated with or without $0.5 \mu \mathrm{M}$ of SB203580 for $1 \mathrm{~h}$ before the addition of RADD $(0-10 \mu \mathrm{g} / \mathrm{ml})$. After $24 \mathrm{~h}$ of incubation, MTT assay was used to determine the viable cells. Optical density at $570 \mathrm{~nm}$ was read on a microplate reader. Inhibition of proliferation was calculated as a percentage of control cultures that were not treated with RADD. The effect of $\mathrm{SB} 202190$ on B16F10 proliferation was represented by $0 \mu \mathrm{g}$ of RADD. The effect was statistically significant at ${ }^{*} \mathrm{P}<0.05$.

cytosolic proteins of the glycolytic pathway, such as triosephosphate isomerase, $\alpha$ enolase, malate dehydrogenase and glyceraldehyde-3-phosphate dehydrogenase; iii) hemoglobin subunit $\beta-1$, which is active in oxygen transport processes; iv) tropomyosin 3, an actin-related protein and v) the mitochondrial protein glutamate dehydrogenase. Among the RADD binding proteins identified, p38 kinase, which is important in the signal transduction pathway, was selected to investigate its role in the effect of RADD on melanoma cell proliferation.

Involvement of p38 kinase in the anti-proliferative effect of RADD on melanoma cells. P38 kinase is involved in multiple cellular processes such as cell cycle progression, growth, metastasis and differentiation (15) and its physiological role in the effect of RADD on melanoma cells was investigated. Different concentrations of RADD were incubated with melanoma cells and the phosphorylation state of p38 kinase in the melanoma cells was examined by Western blot analysis. As illustrated in Fig. 4A, RADD treatment resulted in the phosphorylation of p38 kinase in a dose-dependent manner. Analysis with an antibody against total p38 showed that this treatment did not significantly modify the total levels of the p38 protein. This suggested that RADD treatment induced the activation of p38 kinase in melanoma cells.

The proliferation of melanoma cells decreased with increasing RADD concentrations and the 50\% inhibitory concentration $\left(\mathrm{IC}_{50}\right.$ ) was $7.5 \mu \mathrm{g} / \mathrm{ml}$ (Fig. 4B). However, when SB203580, the specific p38 inhibitor, was added to the melanoma cells before adding RADD (Fig. 4B), it was surprising to observe that SB203580 did not prevent melanoma cell proliferation at $0.5 \mu \mathrm{M}$. Although, with the presence of $10 \mu \mathrm{g} / \mathrm{ml}$ or $7.5 \mu \mathrm{g} / \mathrm{ml}$ of RADD, the inhibitory rate decreased from 60.9 to $48.1 \%$ and from 50 to $36.8 \%$, respectively. These results demonstrate that RADD inhibits melanoma cell proliferation by the activation of $\mathrm{p} 38$ kinase.

\section{Discussion}

In this study, we present evidence that eight different kinds of proteins specifically bind to RADD in vitro. We further demonstrated that RADD treatment resulted in the phosphorylation of p38 kinase and that the p38 inhibitor, SB203580, could decrease the inhibitory effect of RADD on the proliferation of melanoma cells. These results indicate that p38 kinase is involved in the anti-proliferative effect of RADD. p38 MAP kinase is one of the mitogen-activated protein kinases (MAPKs) and has four isoforms, p38 $\alpha$, p38ß, p38 $\gamma$ and p388, in humans and mice. p38 MAP kinase can be 
activated by a wide variety of extracellular signals including pro-inflammatory cytokines and exposure to the environment (15). In this study, RADD treatment led to an increase in p38 kinase phosphorylation, although the total p38 kinase level was unchanged (Fig. 4A). Furthermore, the specific p38 kinase inhibitor, SB203580, decreased the inhibitory effect of RADD on melanoma cell proliferation (Fig. 4B). This suggests that p38 kinase is involved in the anti-proliferative effect of RADD on melanoma cells. Many studies have concentrated on the relationship between ADAM and the p38 MAPK signaling pathway and it has been shown that ADAM can activate the ERK/p38 pathway via fibronectin (FN) and mediate cell proliferation and invasion in hepatocellular carcinoma (16). The non-amyloidogenic pathway activated by IL-1 $\alpha$ in human astrocytic cells was also found to release APP and p38 MAPK with ADAM17 mediation (17). It has been demonstrated that ADAM9 is able to interact directly with the $\alpha_{v} \beta_{3}$ integrin in osteoblasts and, thus, to regulate IL-6 production via the p38 MAPK pathway (18). However, recently, $\mathrm{Lu}$ et al found that the ADAM15 disintegrin domain (ddADAM-15) does not interfere with the PI3 or p38 kinase signaling pathway to inhibit airway smooth muscle cell (ASMC) migration (19). In contrast, evidence that p38 kinase suppresses melanoma cell proliferation has also been demonstrated via a variety of compounds (20).

However, little is known about how RADD interacts with p38 kinase since the molecular weight of RADD is higher than $10 \mathrm{kDa}$ (Fig. 1B) so that it does not transfer into the cell to directly interact with p38 kinase. In this study, RADD was able to target p38 kinase perhaps because it could be translocated intracellularly by endocytic trafficking, an important physiological process of the cell that enables it to utilize macromolecules (such as proteins) or hydrophobic substances. Similar phenomena have been reported for some other proteins. For example, AMPA receptors were shown to be able to enter into cells by endocytosis modulated by p38 kinase (21). Furthermore, p38 MAPK activation is required for the endocytosis of the $\mu$ opioid receptor (MOR) and is sufficient in triggering its constitutive internalization in the absence of agonist (22). One of the mechanisms by which p38 MAPK regulates receptor endocytosis under physiological conditions is the phosphorylation of Rab5 effectors (22).

In this study, RADD was expressed and its affinity with $\alpha_{v} \beta_{3}$ was confirmed by solid-phase adhesion assays (Figs. 1 and 2); similar results have been published in many other studies. The RGD motif in the ADAM15 disintegrin domain can interact with the integrins $\alpha_{v} \beta_{3}$ and $\alpha_{5} \beta_{1}$ in haemopoietic and melanoma cells (2). Zhang et al (23) and Lu et al (24) have demonstrated that the recombinant ADAM15 disintegrin domain expressed in $E$. coli can bind to $\alpha_{v} \beta_{3}$ and similar binding activity for the recombinant domain was also observed in a Pichia pastoris system (12). However, b-RADD showed a similar physiological role to RADD with respect to $\alpha_{v} \beta_{3}$ binding to vitronectin and, thus, in the protein pull-down assay it can be used as bait to capture the binding partners from the whole melanoma cell extracts.

In summary, eight specific binding proteins of RADD were screened by in vitro protein pull-down assay and 2DE-MS methods. Furthermore, p38 kinase was demonstrated to be involved in the RADD anti-proliferative effect on melanoma cells. The results presented here facilitate the further elucidation of the molecular mechanisms underlying the anticancer effect of RADD as well as the development of novel anti-cancer drugs.

\section{Acknowledgements}

This study was supported by a grant from The National Natural Science Foundation of P.R. China (No: 30772586).

\section{References}

1. Arribas J, Bech-Serra JJ and Santiago-Josefat B: Adams, cell migration and cancer. Cancer Metastasis Rev 25: 57-68, 2006.

2. Nath D, Slocombe PM, Stephens PE, Warn A, Hutchinson GR, Yamada KM, Docherty AJ and Murphy G: Interaction of metargidin (adam-15) with alphavbeta3 and alpha5beta1 integrins on different haemopoietic cells. J Cell Sci 112: 579-587, 1999.

3. Kratzschmar J, Lum L and Blobel CP: Metargidin, a membraneanchored metalloprotease-disintegrin protein with an rgd integrin binding sequence. J Biol Chem 271: 4593-4596, 1996.

4. Kuphal S, Bauer R and Bosserhoff AK: Integrin signaling in malignant melanoma. Cancer Metastasis Rev 24: 195-222, 2005.

5. Buckley CD, Doyonnas R, Newton JP, Blystone SD, Brown EJ, Watt S and Simmons DL: Identification of alpha $\mathrm{v}$ beta 3 as a heterotypic ligand for cd31/pecam-1. J Cell Sci 109: 437-445, 1996.

6. Trochon-Joseph V, Martel-Renoir D, Mir LM, Thomaïdis A, Opolon P, Connault E, Li H, Grenet C, Fauvel-Lafève F, Soria J, Legrand C, Soria C, Perricaudet M and Lu H: Evidence of antiangiogenic and antimetastatic activities of the recombinant disintegrin domain of metargidin. Cancer Res 64: 2062-2069, 2004.

7. Kuefer R, Day KC, Kleer CG, Sabel MS, Hofer MD, Varambally S, Zorn CS, Chinnaiyan AM, Rubin MA and Day ML: Adam 15 disintegrin is associated with aggressive prostate and breast cancer disease. Neoplasia 8: 319-329, 2006.

8. Berggård T, Linse S and James P: Methods for the detection and analysis of protein-protein interactions. Proteomics 7: 2833-2842, 2007.

9. Gygi SP, Corthals GL, Zhang Y, Rochon Y and Aebersold R: Evaluation of two-dimensional gel electrophoresis-based proteome analysis technology. Proc Natl Acad Sci USA 97: 9390-9395, 2000.

10. Tingting P, Caiyun F, Zhigang Y, Pengyuan Y and Zhenghong Y: Subproteomic analysis of the cellular proteins associated with the 3' untranslated region of the hepatitis c virus genome in human liver cells. Biochem Biophys Res Commun 347: 683-691, 2006.

11. Maier TJ, Janssen A, Schmidt R, Geisslinger G and Grösch S: Targeting the beta-catenin/apc pathway: A novel mechanism to explain the cyclooxygenase-2-independent anticarcinogenic effects of celecoxib in human colon carcinoma cells. FASEB J 19: 1353-1355, 2005.

12. Jeon OH, Kim D, Choi YJ, Kim SH, Choi WS and Kim DS: Novel function of human adam 15 disintegrin-like domain and its derivatives in platelet aggregation. Thromb Res 119: 609-619, 2007.

13. Janssen A, Schiffmann S, Birod K, Maier T, Wobst I, Geisslinger $G$ and Grösch S: P53 is important for the antiproliferative effect of ibuprofen in colon carcinoma cells. Biochem Biophys Res Commun 365: 698-703, 2008.

14. Wang XX, Liu R, Jin SQ, Fan FY and Zhan QM: Overexpression of aurora-a kinase promotes tumor cell proliferation and inhibits apoptosis in esophageal squamous cell carcinoma cell line. Cell Res 16: 356-366, 2006.

15. Dhillon AS, Hagan S, Rath O and Kolch W: Map kinase signalling pathways in cancer. Oncogene 26: 3279-3290, 2007.

16. Matsuo M, Sakurai H, Ueno Y, Ohtani O and Saiki I: Activation of mek/erk and pi3k/akt pathways by fibronectin requires integrin alphav-mediated adam activity in hepatocellular carcinoma: A novel functional target for gefitinib. Cancer Sci 97: 155-162, 2006.

17. Bandyopadhyay S, Hartley DM, Cahill CM, Lahiri DK, Chattopadhyay N and Rogers JT: Interleukin-1alpha stimulates non-amyloidogenic pathway by alpha-secretase (adam-10 and adam-17) cleavage of app in human astrocytic cells involving p38 map kinase. J Neurosci Res 84: 106-118, 2006. 
18. Karadag A, Zhou M and Croucher PI: Adam-9 (mdc-9/meltringamma), a member of the a disintegrin and metalloproteinase family, regulates myeloma-cell-induced interleukin-6 production in osteoblasts by direct interaction with the alpha(v)beta5 integrin. Blood 107: 3271-3278, 2006.

19. Lu D, Xie S, Sukkar MB, Lu X, Scully MF and Chung KF: Inhibition of airway smooth muscle adhesion and migration by the disintegrin domain of adam-15. Am J Respir Cell Mol Biol 37: 494-500, 2007.

20. Ordan O, Rotem R, Jaspers I and Flescher E: Stress-responsive jnk mitogen-activated protein kinase mediates aspirin-induced suppression of b16 melanoma cellular proliferation. Br J Pharmacol 138: 1156-1162, 2003.

21. Huang CC, You JL, Wu MY and Hsu KS: Rap1-induced p38 mitogen-activated protein kinase activation facilitates ampa receptor trafficking via the gdi.Rab5 complex. Potential role in (s)-3,5-dihydroxyphenylglycene-induced long term depression. J Biol Chem 279: 12286-12292, 2004.
22. Macé G, Miaczynska M, Zerial M and Nebreda AR: Phosphorylation of eea1 by p38 map kinase regulates mu opioid receptor endocytosis. EMBO J 24: 3235-3246, 2005.

23. Zhang XP, Kamata T, Yokoyama K, Puzon-McLaughlin W and Takada Y: Specific interaction of the recombinant disintegrin-like domain of mdc-15 (metargidin, adam-15) with integrin alphavbeta3. J Biol Chem 273: 7345-7350, 1998.

24. Lu D, Chung KF, Xia M, Lu X, Scully MF and Kakkar V: Integrin binding characteristics of the disintegrin-like domain of adam-15. Thromb Haemost 96: 642-651, 2006. 